


\title{
Reise um die Erde
}

\author{
durch
}

\section{Nord-Asien und die beiden Oceane}

\author{
in den Jahren 1828, 1829 und 1830
}

\author{
a sogefüht
}

von

Adolph Erman.

In einer historischen und einer physikalischen Abtheilung dargestellt und mit einem Atlas begleitet.

$$
\begin{gathered}
\text { B e r l i n, } \\
\text { verlegt be } i \text { t. R e i mer. } \\
\qquad \overline{833} .
\end{gathered}
$$




\title{
Reise um die Erde
}

\author{
durch
}

\section{Nord-Asien und die beiden Oceane}

in den Jahren 1828, 1829 und 1830

\author{
ausgeführt \\ ron \\ Adolph Erman.
}

Erste Abtheilung:

\section{Historischer Bericht.}

$$
\text { Erster Band. }
$$

Reise von Berlin bis zum Eismeere im Jahre 1828.

$$
\begin{aligned}
& \text { B erlin, } \\
& \text { verlegt be i G. ke imer. } \\
& \frac{1833}{}
\end{aligned}
$$



Seiner Majestät dem Könige

\section{Friedrich Wilhelm III.}

$\operatorname{sen} \theta m$

\section{allergnädigsten Könige und Herrn}

in ehrfurchtvollster Unterthänigkeit

$$
\text { der Verfasser. }
$$


